\title{
The Study of Breastfeeding Knowledge among Northern Iranian Teachers
}

\author{
Veghari $\mathbf{G}^{1}$, Mansourian $\mathbf{A}^{2}$ \\ ${ }^{1}$ Gholamreza Veghari, Assistant Prof. of Nutrition, ${ }^{2}$ Azadreza Mansourian, PhD in Clinical Biochemistry. Both from the \\ the Department of Biochemistry and Nutrition, Golestan University of Medical Sciences.
}

Address for correspondence: Gholamreza Veghari, E-mail: grveghari@yahoo.com

\begin{abstract}
Introduction: Breastfeeding provides all essential nutrients for the first 6 months of life and plays an important role in ensuring health in neonates and mothers. This study was carried out among northern Iranian primary school teachers to determine the knowledge about breastfeeding. Materials and Methods: This is a descriptive- crossectional study and where 745 subjects were chosen by random and cluster sampling. Data was collected by questionnaire about social-demographic and the optimal food awareness at fist 6 months of age. Data was analyzed by SPSS win soft-war. Chi-2 test was used to compare groups. Results: Teacher's knowledge about exclusive breastfeeding and breastfeeding with breast milk substitutes as the best diet was $81.6 \%$ and $17.6 \%$, respectively. There was no statistical difference between the teachers who were non-university graduates $(78.0 \%)$ or those who were university graduates (83.3\%). The knowledge of breastfeeding among Turkman and Non-Turkman was $85.1 \%$ and $80.2 \%$ and male to female was $80.6 \%$ and $82.6 \%$, respectively. There were no statistical differences between these variables. Conclusion: The teacher's knowledge about advantages of breastfeeding was low and that it was influenced by social-economic factors. Further studies need to be carried out in this area for determining the difficulties of breastfeeding.
\end{abstract}

Keyword: Breastfeeding, Teacher, Knowledge, Ethnicity, Iran

\section{Introduction}

$\mathrm{T}$ he main food of most infants is breast milk in the form of nature's gift. Breastfeeding is well established in Iran, and the history of it can be traced back to the fourth century in the Canon Medicine Text book which was written by Avicenna ${ }^{1}$. Iran is a Muslim country and Islam emphasis the feeding of human milk instead of animal milk $^{2}$. For the first 6 months, breastfeeding meets the requirement of the child in full ${ }^{3}$. Polyunsaturated fatty acids secreted in the milk are required for nerve cell and brain development ${ }^{4}$. Breastfeeding makes an emotional connection between mother and baby which is followed till adulthood ${ }^{5}$. Infectious disease and mortality rate are low among children that have been breastfeed for more than 12 months $^{6}$. Variables that may influence breast feeding includes: race, maternal age, maternal work, level of education of parents, social-economic status, insufficient milk supply, infant health problem, maternal obesity, smoking, parity, method of delivery, maternal interest and other related factors ${ }^{7}$.

Based on the Health and Disease study in Iran in 2000 AD, nearly $90 \%$ of children received breast milk and subsequent studies showed that exclusive breastfeeding reduced from $44 \%$ in 2000 to $27 \%$ in $2004^{8}$. Literacy has played a main role for promotion and expansion of health program and influence of education on nutritional program has been approved by some studies but the influence of education on the nutritional status can be different different. For example, in spite of Dyson's study ${ }^{10}$ which reported that the teaching mothers who had premature infants were affected on the early breastfeeding but Gill's study ${ }^{11}$ didn't show similar results. Other studies ${ }^{12,13,14}$ showed that duration of breast feeding was more 
in educated women. Huus and et $\mathrm{al}^{15}$ in their study showed that exclusive breastfeeding (under 4 months) in parents who had had college education was still low. Teachers from each community are educated and aware of their good nutritional practices and can directly or indirectly change the social attitudes in the community. Golestan province is located in northern Iran which has a population of $1,600,000$. This area is located within the hill side of Alborze mountains ${ }^{18}$ and has 159442 school children at the primary level in 2149 schools and 15000 primary school teachers. In this province various people residing from different ethnic groups, predominantly, Fars (native), Turkman, Sistani and Bluch.

Due to the restriction in executing epidemiological projects in many of those areas, there has not been any study on the teacher's knowledge and attitude in this area up till now; therefore it was necessary to design a study about the same. The aims of this study were to examine the knowledge and attitude of primary school teachers about breastfeeding with the variables of educational level, age, sex, ethnicity, economic status and marital status in the north of Iran in 2008.

\section{Methods}

This was a descriptive and cross-sectional research study, and carried out amongst 745 primary school teachers (399 male and 346 female) from 112 schools of villages in northern Iran. The schools and teachers were chosen by cluster and stratified sampling. For all teachers a questionnaire was filled which contained questions on the knowledge about breastfeeding. Sociodemographic criteria such as gender, ethnicity, economical condition and marital status were also recorded.

The ethnic groups in this study were divided into two groups:

1) Turkman: The inter marriage of this ethnic group with other ethnic groups were rare, therefore called as a pure race.

2) Non Turkman: The native residents of this area who are called the same name in this society

Educational level: The educational level of teachers based on Iranian categorization was divided into 2 groups

1) Low Educated: Teachers who educated for 12 years schooling.
2) High Educated: $>12$ years of education including those teachers who were educated in college.

Age divided into 4 groups:

$\leq 30$ years, $31-40$ years, $41-50$ years and $51 \geq$.

\section{Marital status divided two groups}

Married and Unmarried. Divorcees were included into the married group.

\section{Economic status}

The economic ranking of the families in this study, were assessed on the base of 12 items and principles. On the bases of those 12 items the family was divided two groups.

Owner more than 9 items as good economic and Owner less than 9 items as intermediate economic.

Data were analyzed using SPSS version 16.0 and statistical significance was defined as $p$-value $<0.05$. Chi-2 test was used to compare group frequencies.

\section{Results}

Questionnaires were completed for all of cases. There were $11.1 \%$ and $5.2 \%$ in under 30 years and over 50 years age groups, respectively out of which $7 \%$ were unmarried. Mean \pm SD of age in women were $37.52 \pm 7.53$ years and in men $42.15 \pm 6.77$ years age. Also, $61.7 \%$ and $38.3 \%$ of teachers were living in urban and rural areas respectively and 10 women were pregnant.

The relationship between socio-demographic factors and teacher's knowledge is presented as in Table 1. The rate of knowledge about benefits of breastfeeding in the first 6 months of life was $81.6 \%$. Breastfeeding beside other milk or milk substitutes were considered appropriate by $17.6 \%$ of them. Knowledge about exclusive breast feeding was found in $2.2 \%$ in women more than men.. Turkman ethnic group were $4.9 \%$ more than other ethnic groups. College educated group were $2.7 \%$ more than low educated group and good economic status group were $2.7 \%$ more than intermediate economic status group. Also, knowledge about breastfeeding was found more in 31-40 years aged group as compared to other age groups. There was no statisticallly significant difference between the above mentioned groups. 
Table 1: The relationship between socio-demographic factors and advantage of breastfeeding knowledge in primary school teachers.

\begin{tabular}{|c|c|c|c|c|c|c|}
\hline \multicolumn{2}{|l|}{ Characteristics } & \multirow{2}{*}{$\begin{array}{c}n=745 \\
399\end{array}$} & \multirow{2}{*}{$\begin{array}{c}\text { Breast milk } \\
320(80.6)\end{array}$} & \multirow{2}{*}{$\begin{array}{c}\begin{array}{c}\text { Breast Milk \& others } \\
\text { milk substitutes }\end{array} \\
75(18.9)\end{array}$} & \multirow{2}{*}{$\begin{array}{c}\text { Unknown } \\
4(1.1)\end{array}$} & \multirow{3}{*}{$\frac{p \text {-value }}{0.258}$} \\
\hline \multirow{2}{*}{ Gender } & Male & & & & & \\
\hline & Female & 346 & $288(82.8)$ & $56(16.1)$ & $2(0.5)$ & \\
\hline \multirow[t]{2}{*}{ Ethnicity } & Turkman & 215 & $183(85.1)$ & $31(14.4)$ & $1(0.5)$ & \multirow{2}{*}{0.115} \\
\hline & Non-Turkman & 530 & $425(80.2)$ & $100(18.9)$ & $5(0.9)$ & \\
\hline \multirow{4}{*}{ Age(year) } & $\leq 30$ & 83 & $67(80.7)$ & $16(19.3)$ & $0(0)$ & \multirow{4}{*}{0.378} \\
\hline & $31-40$ & 310 & $262(84.5)$ & $46(14.8)$ & $2(0.6)$ & \\
\hline & $41-50$ & 313 & $248(79.2)$ & $61(19.5)$ & $4(1.3)$ & \\
\hline & $\geq 51$ & 39 & $31(79.5)$ & $8(20.5)$ & $0(0)$ & \\
\hline \multirow{2}{*}{ Educational Level } & Low & 263 & $184(78.0)$ & $50(21.2)$ & $2(0.8)$ & \multirow{2}{*}{0.080} \\
\hline & High & 509 & $424(83.3)$ & $81(15.9)$ & $4(0.8)$ & \\
\hline \multirow{2}{*}{ Economic Status } & Intermediate & 458 & $369(80.6)$ & $85(18.6)$ & $4(0.9)$ & \multirow{2}{*}{0.353} \\
\hline & Good & 287 & $239(83.3)$ & $46(16.0)$ & $2(0.7)$ & \\
\hline \multirow{2}{*}{ Marital Status } & Single & 52 & $42(80.8)$ & $9(17.3)$ & $1(1.9)$ & \multirow{2}{*}{0.870} \\
\hline & Married & 693 & $566(81.7)$ & $122(17.6)$ & $5(0.7)$ & \\
\hline \multicolumn{2}{|l|}{ Total } & 745 & 131(81.6) & $608(17.6)$ & $6(0.8)$ & \\
\hline
\end{tabular}

\section{Discussion}

In this study, one to five of the teachers did not have enough knowledge about advantages of breastfeeding and $17.6 \%$ of them prefered that children consumed breast milk with cow's milk or powder milk. Breast feeding has an important role on the physical and mental growth of infsnts $3,4,19,20$. Gill's study has showed ${ }^{11}$ that family members can impose a positive influence during the breast feeding period. Pisacane's study ${ }^{16}$ showed that training of parents about adventages of breastfeeding and their obstacles can enhance the duration of exclusive breastfeeding. A study ${ }^{21}$ showed that Women with high education level, married, not experiencing financial stress and who attended prenatal classes were more likely to initiate breastfeeding. Teachers in developing and Islamic countries are respectable; thereby the positive impact of this group on the change of social behavior is undeniable.

In the present study, knowledge about advantages of breastfeeding in high educated teachers was more. Others studies ${ }^{12,13,14}$ showed that the duration of breastfeeding in high educated women was more but Huus ${ }^{15}$ showed that exclusive breastfeeding in college educated mothers is shorter as compared to low educated mothers.

It is notable, if the knowledge in high educated mothers is more, but the outdoor social activity in this group is more. The limitations of this study were that we only assessed the knowledge of primary school teachers regarding breast feeding practices but not the obstacles to breastfeeding. In this study, knowledge about breast feeding advantages among Turkman ethnic group was higher than non-Turkmen ethnic group. Researchers approve the influence of ethnicity on breastfeeding promotion. Lesser tendency of breastfeeding was shown by Forste ${ }^{22}$ and $\mathrm{Liu}^{23}$ in their studies. Also, Jevitt ${ }^{24}$ showed that breastfeeding duration in obese block women was shorter than US and Spanish immigrant women. Some studies ${ }^{25,26}$ carried out in this area of Iran showed that nutritional status in Turkman ethnic group was different as compared to other ethnic groups.

In our study, knowledge in high economic group was higher than intermediate economic group. Other studies $^{27,28}$ showed that the breastfeeding duration was low in low income families. Evers an et $\mathrm{al}^{21}$ in their study showed that low-income households, who had good awareness, had more tendency to breastfeed their children.

\section{Conclusion}

Contrary to what we thought, only one-fifth of teachers were aware about the advantages of breast feeding. Unlike other studies we didn't have any significant relationship between socio-demographic factors and knowledge about advantages of breastfeeding. With regard to the influence of teachers in changing the social behavior, a training program for improving knowledge of breastfeeding is suggested 


\section{Acknowledgements}

The authors would like to thank the medical and administrative staff in the Primary Health Care Centers of Golestan University of Medical Sciences and Golestan Organization of Education for their valuable assistance during the field work.

\section{Funding: Nil}

Conflict of Interest: Nil

Permission from IRB: Yes

\section{References}

1. Modanlou HD: Avicenna (AD 980 to 1037) and the care of the newborn infant and breastfeeding. $J$ Perinatol 2008; 28(1):3-6.

2. Raisler J, Alexander C, O'Campo P. Breast-feeding and infant illness: a dose-response relationship? Am J Public Health 1999;89(1):25-30

3. Nurturing the future: challenges to breastfeeding in the 21st century; 23-27 September 2002, Arusha, Tanzania. Penang: World Alliance for Breastfeeding Action; 2004.

4. Innis SM: Prenatal biochemistry and physiology of long-chain polyunsaturated fatty acids. J Pediatr 2003;143(4 Suppl):S1-8.

5. Asaei M, Esfehani MM, Oladi B, Bahrami M, Parsai S, Khatami Gh $R$, et al. What we should know about infant feesing. A guide for mother \& health professionals. World Health Organization (WHO) \& IRI Breastfeeding Promotion Society; 1999. [Persian].

6. Burns C. Pediatric Primary Care. 2th ed. USA of America; W.B.Saunders. Philadelphia.2000.

7. Diane Thulier and Judith Mercer. Variables Associated With Breastfeeding Duration. J Obstet Gynaecol Neonatal Nursing 2009;38:259-268. Article URL[Article URL[http://jognn.awhonn.org ]

8. The Ministry of Health IR of Iran, Breastfeeding office [http://www.bfps.ir/(i5emlr45w1kdeg45tov0ysem) / Persian/Home.aspx]

9. Marandi A, Afzali HM, Hossaini AF: The reasons for early weaning among mothers in Teheran. Bull World Health Organ 1993;71(5):561-569.

10. Dyson, L., Mccormick, F., \& Renfrew, M. J. Interventions for promoting the initiation of breastfeeding. Cochrane Database of Systematic Reviews. 2005;18(2), CD001688.
11. Gill, S. L., Reifsnider, E., \& Lucke, J. F. Effects of support on the initiation and duration of breastfeeding. Western Journal of Nursing Research. 2007; 29(6), 708-723.

12. Scott JA, Binns CW. Factors associated with the initiation and duration of breastfeeding: A review of the literature. Breastfeed Review 1999;7:5-16.

13. Susin L RO, Giugliani E R J, Kummer SC, Maciel M, Simon C, da Silveira LC, et al. Does parental breastfeeding knowledge increase breastfeeding rates? Birth 1999;26(3):149-156.

14. Hass DM, Howard CS, Christopher M, Rowan K, Broga MC, Corey T. Assessment of breastfeeding practices and reasons for success in a military community hospital. J Human Lactation 2006;22:439-445.

15. Huus K, Ludvigsson JF, Enskär K, Ludvigsson J. Exclusive breastfeeding of Swedish children and its possible influence on the development of obesity: a prospective cohort study. BMC Pediatr 2008;8:42.

16. Pisacane A, Continisio GI, Aldinucci M, D'Amora $S$, Continisio P. A controlled trial of the father's role in breastfeeding promotion. Pediatrics 2005;116(4):e494-e498.

17. Scott JA, Binns CW, Oddy WH, Graham KI. Predictors of breastfeeding duration:mevidence from a cohort study. Pediatrics 2006;117(4):e64655.

18. Statistical Center of Iran. Population and Housing Census. Available from http://www.sci.org.ir].

19. Kramer MS, Fombonne E, Igumnov S, Vanilovich I, Matush L, Mironova E, et al. Promotion of Breastfeeding Intervention Trial (PROBIT) Study Group. Effects of prolonged and exclusive breastfeeding on child behavior and maternal adjustment: evidence from a large, randomized trial. Paediatrics 2008;121(3):e435-40.

20. Kramer MS, Aboud F, Mironova E, Vanilovich I, Platt RW, Matush L, et al. Promotion of Breastfeeding Intervention Trial (PROBIT) Study Group. Breastfeeding and child cognitive development: new evidence from a large randomized trial. Arch Gen Psychiatry 2008;65(5):578-84.

21. Evers S, Doran L, Schellenberg K. Influences on breastfeeding rates in low-income communities in Ontario. Canadian J Public Health 1998;89:203207. 
22. Forste R, Weiss J, Lippincott E. The decision to breastfeed in the United States: Does race matter? Pediatrics 2001;108:291-296.

23. Liu J, Smith MG, Dobre MA, Ferguson JE. Maternal obesity and breast-feeding practices among white and black women. Obesity 2010;18(1):175-82.

24. Jevitt C, Hernandez I, Groër M. Lactation complicated by overweight and obesity: supporting the mother and newborn. J Midwifery Women's Health 2007;52(6):606-13.

25. Veghari GR, Mansourian. AR. The Comparative Study of Obesity among Mothers with Different
Ethnic Groups in Northern IRAN. Iranian J Pub Health 2007;36(3):71-76.

26. Veghari G. Anemia in north of Iran (south-east of Caspian Sea). Pak J Biol Sci 200715;10(10):1703-7.

27. Coulibaly R, Seguin L, Zunzunegui MV, Gauvin L. Links between maternal breast-feeding duration and Quebec infants' health: A population-based study, are the erects di،erent for poor children? Maternal Child Health J 2006;10:537-543.

28. Dennis CL. The breastfeeding self-efficacy scale: Psychometric assessment of the short form. J Obstetr Gynecol Neonatal Nursing 2003;32:734744.

\section{How to cite this article?}

Veghari G, Mansourian A. The Study of Breastfeeding Knowledge among Northern Iranian Teachers. J Nepal Paedtr Soc 2011;31(1):39-43. 